\title{
Losurdo, Domenico Um mundo sem guerras: a ideia de paz,das promessas do passado às tragédias do presente
}

Fernando Mattiolli Vieira*

Trad. Ivan Esperança Rocha. São Paulo: Ed. Unesp, 2018. 434 p.

O ano de 2019 certamente não será recordado pela ocorrência de grandes avanços em favor da paz mundial. Na África, a Líbia não conseguiu superar a instabilidade política instaurada com a derrubada de Muammar Kadhafi, em 2011, e a disputa pelo poder transformou-se em uma extensa guerra civil desde então. Naquele mesmo ano, no Oriente Médio, a Síria de Bashar Al-Assad foi arrastada para um conflito envolvendo agentes internos e externos, e até este momento o país devastado se defronta com o enfrentamento de grupos antagônicos que impedem a pacificação do país. No sul da Ásia, Índia e Paquistão, mais uma vez, despertam a tensão mundial com a possibilidade de um conflito nuclear após bombardeios e ataques aéreos mútuos, na Caxemira, no início de 2019. Esses e vários outros conflitos, que de formas diferentes marcam a ausência de paz entre povos, se inserem na continuidade dos acontecimentos que foram apontados pelo historiador e filósofo italiano Domenico Losurdo em sua obra Um mundo sem guerras: a ideia de paz, das promessas do passado às tragédias do presente ( $1^{\text {a }}$ ed. italiana, 2016). Esse foi um de seus últimos trabalhos, disponível agora em português pela editora da Unesp, traduzido pelo professor Ivan Esperança Rocha (Unesp-Assis).

O livro é um trabalho de História Política sobre o Ocidente que considera cinco momentos históricos inter-relacionados: a Revolução Francesa, o período de atuação da Santa Aliança, o desenvolvimento do comércio mundial e das sociedades industriais do século XIX, a Revolução Russa e, por fim, o período da hegemonia norte-americana, desde a Primeira Guerra Mundial até os acontecimentos após a Guerra Fria. Alguns dos temas mais importantes que perpassam toda a profícua produção bibliográfica de Losurdo, como a crítica

\footnotetext{
* Universidade de Pernambuco (UPE), Petrolina, PE, Brasil. khirbet.qumran@gmail.com <https:// orcid.org/0000-0001-5308-1471>
} 
ao liberalismo e ao colonialismo, o nacionalismo e os processos revolucionários, são desenvolvidos em sua relação com as propostas de paz apresentadas nesses cinco momentos. ${ }^{1}$

Do início ao fim do livro, filósofos, historiadores, políticos e jornalistas são colocados em diálogo contínuo a fim de se identificar quando e como foram construídas determinadas tradições de paz ao longo do tempo. Os discursos são retirados de qualquer isolamento histórico, sendo confrontados diacrônica e sincronicamente. As propostas de paz defendidas são contextualizadas e aproximadas a acontecimentos históricos contemporâneos - esse é o fato que, para Losurdo, determina a credibilidade do discurso dos pensadores. O método se torna o grande mérito do autor: identificar a origem de tradições que, na maior parte dos casos, eram sobretudo retóricas e levavam os Estados a se convencerem de um destino imperialista. Por exemplo, as perspectivas de paz perpétua do filósofo e economista John Stuart Mill, do presidente norte-americano Thomas Woodrow Wilson e do filósofo Jürgen Habermas, cada uma a seu tempo, refletem o apoio a um processo civilizador de Estado que incluía a submissão do outro e a pacificação pela guerra. Daí o resultado de uma equação histórica sobre as propostas de paz: é preciso fazer uma clara distinção entre autênticos projetos de paz duradoura e ambições mal camufladas de despotismo mundial (p. 49).

Para chegar às suas conclusões, Losurdo mantém a tradição política que define a guerra como algo mais amplo do que um conflito entre exércitos de Estados. A famosa "fórmula" do militar-burocrata prussiano Carl von Clausewitz, "A guerra é a continuação da política por outros meios" (Clausewitz, 1979, p. 65), perpassa toda a obra de Losurdo como um paradigma necessário para ampliar o conceito de guerra. Ela também é econômica, comercial, psicológica, "clandestina". As formas de um Estado capitalista e democrático apresentá-la ao longo dos últimos dois séculos é puramente contraditória à noção de civilidade desenvolvida por/para ele mesmo. Por isso, a guerra é necessariamente refletida e executada "por outros meios", de forma dissimulada; afinal, a selvageria de um conflito armado é um costume decadente que só pode ser atribuído ao outro: ao povo guerreiro, arcaico, estranho aos costumes ocidentais. A guerra, realizada pelo Ocidente sob a égide da paz, se transmuta em "operação de segurança”, em "intervenção", em "manutenção da paz" (Crettiez, 2011, p. 68-69).

$\mathrm{O}$ autor não se esquiva de questões bastante sensíveis, próprias do aprofundamento do tema. A meu ver, a principal delas - cara a diversos pensadores - é: seria justa a intervenção em um Estado que viola os direitos humanos de sua própria população ou de um Estado mais fraco? O cenário político internacional exige, em muitas situações, respostas rápidas e enérgicas que, se não forem tomadas a tempo, podem resultar em grandes catástrofes, como vimos 
recentemente no Oriente Médio, com os avanços do Estado Islâmico contra os curdos e não convertidos, ou em Mianmar, com o massacre da população rohingya, ambos por questões religiosas e étnicas. Situações como essas são facilmente cooptadas por países imperialistas que legitimam suas ações de guerra com amplo apoio dos espectadores internacionais. Losurdo não questiona a validade de uma guerra de proteção e, nesse sentido, reconhece a importância de uma instituição mundial como a ONU. Seu foco, contudo, são os protagonistas que assumem a "responsabilidade de proteger". Para ele, as "ações humanitárias" não devem ser orquestradas por apenas um país e seus aliados, pois a decisão e a execução devem encontrar legitimidade apenas se não forem exercidas de maneira unilateral (p. 384).

Mais de um ano após a morte de Losurdo (28 jun. 2018), não há mudanças no quadro internacional. Para ele, o último marco político-econômico global foi o fim da Guerra Fria - o que para Francis Fukuyama representou o "fim da história" e, para Habermas, uma nova "ordem cosmopolita", "supranacional”. Desde aquele momento, Losurdo se mostrou cético para com mudanças em favor da paz - sua desconfiança foi plenamente coerente com o que o cenário mundial apresentou até este momento. Com o fim da Guerra Fria, os Estados Unidos assumem o papel de "xerife internacional", atuando sob um princípio que o filósofo Michael Walzer (2003) chamou de "guerra justa”, uma ação hedionda recoberta por uma concepção moral que justifica atos belicosos. Isso foi visto com a guerra high tech no Iraque, com o embargo econômico à Venezuela e com os impasses comerciais com a China - que para alguns representa a iminência de uma nova "Guerra Fria". Nada aponta para um cenário mais positivo em favor da paz em curto prazo, tendo em vista a retomada da política America First pela atual gestão presidencial naquele país.

Diante das propostas históricas de paz consideradas, Losurdo procura dar resposta a uma questão que possivelmente aguçou nossa escatologia, por questões religiosas ou políticas, em algum momento da vida: haverá algum dia um mundo sem guerras? Para o autor, as experiências do passado, exitosas ou não, não devem ser desprezadas. As revoluções inglesas e a Revolução Americana originaram apenas uma pax imperium, instituindo a dominação sobre outros povos e o colonialismo, utilizando-se de inúmeras guerras para a manutenção e ampliação de seu poderio. Alguns modelos propostos na Revolução Francesa e na Revolução de Outubro, entretanto, apresentaram novos paradigmas que deveriam ser aproveitados, como o desprezo pela escravidão, a aversão ao colonialismo, a defesa da autonomia dos povos e a aproximação deles pela égide da paz. Por isso, Losurdo conclui que há caminhos que podem ser trilhados na direção da paz perpétua, ainda que eles sejam "incertos e problemáticos" e sujeitos a uma "longuíssima duração" (p. 397). 
Para que Um mundo sem guerras seja bem entendido, o próprio autor deve ser inserido em uma tradição: uma tradição marxista, de crítica ao conservadorismo e ao liberalismo, considerados por ele como entraves para as propostas reais e universais de paz perpétua. E um confronto com essas tradições é, deveras, inevitável. No horizonte desse embate, para Losurdo, deveria haver o fim do próprio sistema capitalista, a diminuição gradual do Estado e a estruturação de uma comunidade mundial. Seu ativismo político e sua filiação ao Partido Comunista Italiano podem ser percebidos de maneira bastante coerente e sutil, mas o tom erudito da obra, o profundo embasamento histórico e a lucidez de suas conclusões eliminam qualquer possibilidade de apologia às convicções do autor. Pelo contrário, apresentam-se como um convite à reflexão para o leitor interessado em saber das principais propostas de paz já apresentadas no Ocidente e preocupado com as possibilidades do porvir.

\section{REFERENCIAS}

ARON, Raymond. Paz e guerra entre as nações. Brasília: Ed. UnB, 2002. CLAUSEWITZ, Carl von. Da guerra. São Paulo: Martins Fontes, 1979.

CRETTIEZ, Xavier. As formas de violência. São Paulo: Loyola, 2011.

LOSURDO, Domenico. Contra-História do Liberalismo. São Paulo: Ideias \& Letras, 2006a.

LOSURDO, Domenico. Liberalismo: entre civilização e barbárie. São Paulo: Anita Garibaldi, 2006b.

WALZER, Michael. Guerras justas e injustas: uma argumentação moral com exemplos históricos. São Paulo: Martins Fontes, 2003.

\section{NOTA}

${ }^{1}$ As principais obras de Losurdo foram traduzidas para o português. A crítica ao liberalismo é o fio condutor em todas elas, sendo esse tema mais explorado em Liberalismo: entre civilização e barbárie (LOSURDO, 2006b) e, principalmente, em Contra-História do Liberalismo (LOSURDO, 2006a).

Resenha recebida em 16 de abril de 2019.

Aprovada em 14 de outubro de 2019.

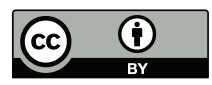

